\title{
Nanostructures in Physical Materials Chemistry: An Exploratory Laboratory
}

\author{
Thomas J. Manning, ${ }^{*}{ }^{\dagger}$ Amy Feldman, ${ }^{\dagger}$ Michael Anderson,,${ }^{\dagger}$ Leri Atwater ${ }^{\dagger}$ Brent Lesile, ${ }^{\dagger}$ Derek \\ Lovingood, ${ }^{\dagger}$ Anna Lee McRae,${ }^{\dagger}$ Rob Stapleton, ${ }^{\dagger}$ Kim Riddle, ${ }^{\dagger}$ Jun Lui, ${ }^{*}$ Thomas Vickers, ${ }^{\S}$ \\ Naresh Dalal, ${ }^{\S}$ and Lambertus J. van de Burgt ${ }^{\S}$
}

\author{
Department of Chemistry,Valdosta State University,Valdosta, GA 31698,tmanning@valdosta.peachnet.edu, \\ Electron Microscope Facility, Biology Department, Florida State University, Tallahassee, Florida, and \\ Department of Chemistry, Florida State University, Tallahassee, Florida
}

Received January 22, 2001 Accepted March 9, 2001

\begin{abstract}
The blend of nanotechnology and material science is often beyond the scope of undergraduate laboratories. Through undergraduate research, graphite-intercalated compounds have been incorporated in the production of carbon-based nanostructures. Based on this work a series of exploratory exercises were designed for the undergraduate physical chemistry laboratory emphasizing nanostructure material science. This rapidly expanding area of science and technology can be introduced at an undergraduate level using a high temperature oven to produce nanostructure samples that are analyzed by Raman spectroscopy, scanning electron microscopy, and transmission electron microscopy at research university laboratories, infrared spectroscopy, and a bomb calorimeter. In these experiments we use samples of pure graphite, fluorinated graphite, and lanthanum oxide to induce the formation of nanostructures. An overview of fullerenes, nanotubes, boron nitride and $\mathrm{Si}$ nanostructures, other carbon forms, graphite-intercalated compounds, and the storage of hydrogen in nanotubes are provided in an appendix. Several extensions of the laboratory are proposed.
\end{abstract}

\section{Introduction}

Fullerenes. In 1985 the existence of a third form of carbon was revealed. Until that discovery, only two forms of carbon were known, diamond and graphite. Smalley, Kroto and Curl at Rice University refined the mass spectrometric analysis of carbon plasma produced by the laser vaporization of graphite disks in a helium atmosphere [1]. A strong peak determined by a mass spectrometer at $720 \mathrm{amu}$ coupled with vibrational and nuclear spectroscopy indicated that a spherical $\mathrm{C}_{60}$ structure had been synthesized. Known as Buckminsterfullerene, fullerene, or buckyballs, the closed-caged $\mathrm{C}_{60}$ structure exhibits perfectly symmetric geometry and is stable at very high temperatures and pressures. The molecule's name, Buckminsterfullerene, is derived from the architectural creator of geodesic domes, R. Buckminster Fuller. This new carbon compound has sparked intense research into the chemistry of $\mathrm{C}_{60}$ [2-14].

In 1991, Japanese researchers discovered tubes of carbon with diameters of 2-4 nm [15]. By passing an electric current between graphite rods in a low-pressure helium atmosphere, nanotubes are created in similar fashion to buckyballs. Variations of these experiments have produced both singlewalled carbon nanotubes (SWNT) and multi-walled nanotubes (MWNT). Graphite rods packed with cobalt, nickel, lanthanum, or iron have been shown to catalyze the production of nanostructures.

\footnotetext{
${ }^{*}$ Address correspondence to this author.

$\dagger$ Department of Chemistry, Valdosta State University

‡ Biology Department, Florida State University

$\S$ Department of Chemistry, Florida State University
}

The synthesis of nanometer-sized particles has extended beyond carbon [2, 10, 16-20]. Other completed work includes nanostructure synthesis with silicon, boron nitride, and various types of metal carbide nanoparticles such as $\mathrm{Fe}_{3} \mathrm{C}, \mathrm{CaC}_{2}$, $\mathrm{Mn}_{3} \mathrm{C}_{7}, \mathrm{SrC}_{2}$, and $\mathrm{LaC}_{2}[2,6-8,21-23]$

Previous work with undergraduates has centered on using graphite-intercalated compounds (GIC) as a starting and intermediate material and $27.12-\mathrm{MHz}$ inductively coupled argon plasma as the heat source in GIC-fluorinated graphite to facilitate conversion to pure carbon nanostructures. Fluorinated graphite $\left(\mathrm{C}_{1} \mathrm{~F}_{1}\right)$ has carbons with $\mathrm{sp}^{3}$ hybridization and irregular spacing between the graphite sheets making it potentially more reactive than closely stacked graphite [19]. In these past studies we were able to synthesize spherical and tubular allotropes of carbon as well as a form of exfoliated graphite of 5-12 $\mathrm{nm}$ that is stable under ambient conditions. We chose to build upon our research to implement an undergraduate nanotechnology laboratory.

Some areas of nanotechnology involve fairly sophisticated synthesis and analytical techniques (i.e., nanoelectronic components, etc.) considered beyond the realm of the undergraduate laboratory; however, we demonstrate the feasibility of bulk nanostructure production in an undergraduate laboratory setting and analysis by using FT-IR, TEM, SEM, and Raman instruments. While students do not use the Raman, TEM, and SEM instruments (samples are shipped for testing), students gain experience in interpreting the visual and spectroscopic data from these instruments. Many academic, government, and industrial research laboratories analyze chemical samples in a similar fashion. 


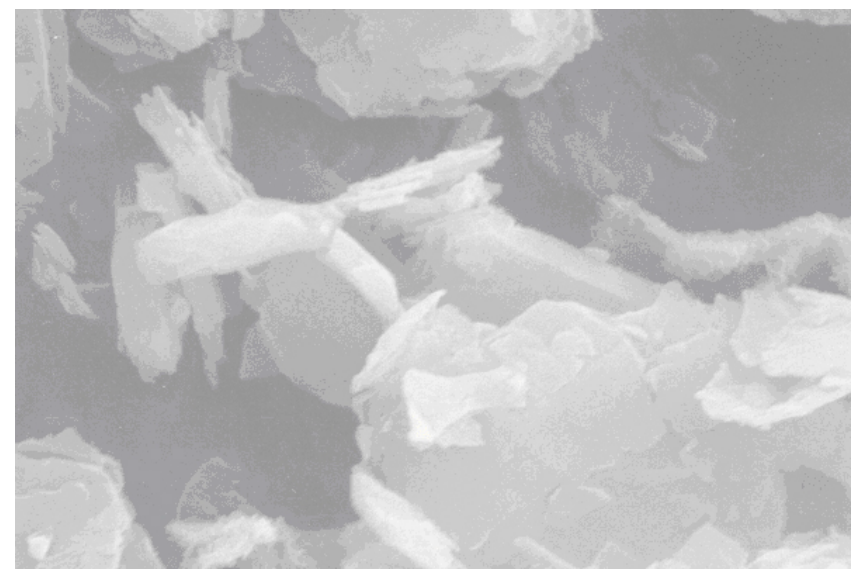

Figure 1. SEM image (10,000 times) of fluorinated graphite dust used as the starting material.
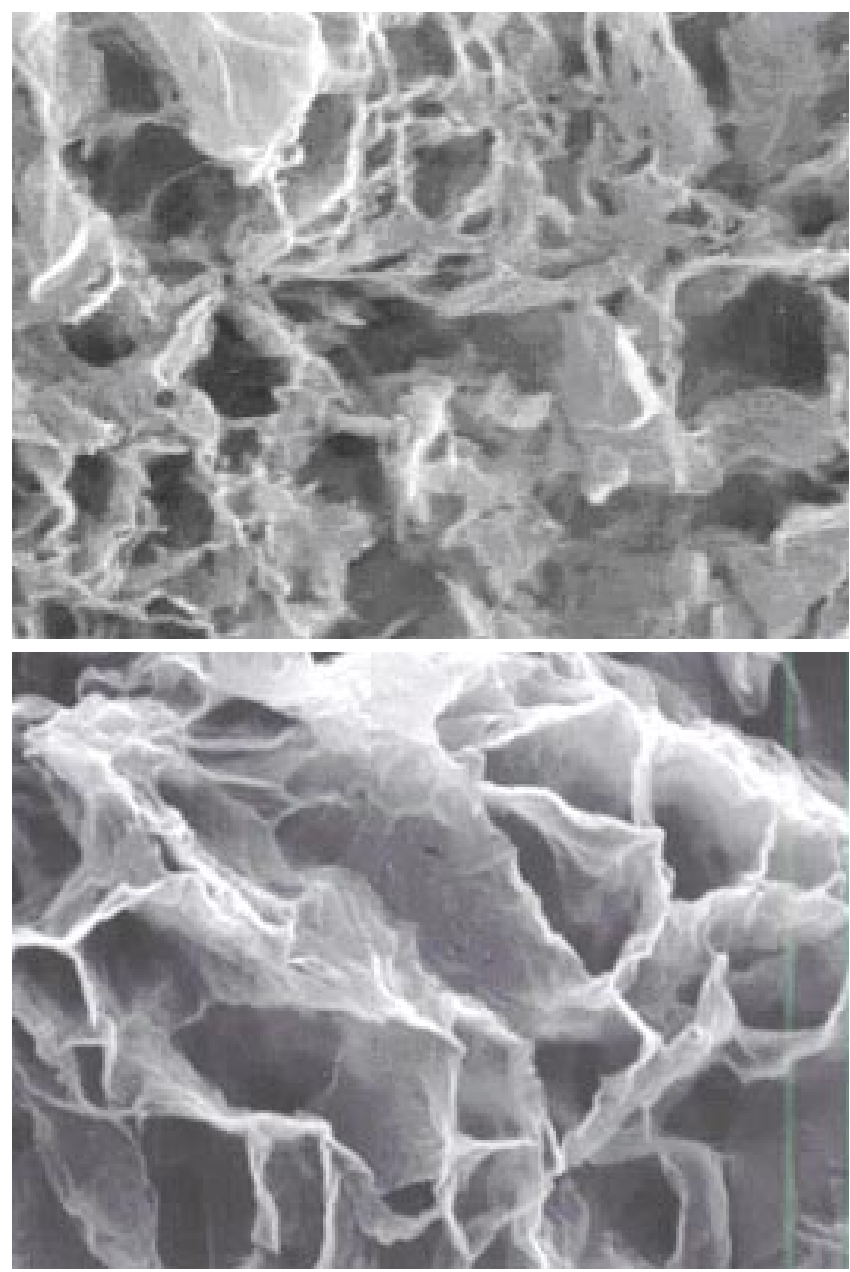

Figure 2. Two SEM images (10,000 times) of exfoliated graphite (EG) produced by the thermal decomposition of fluorinated graphite. The material has a large surface area and low density. The graphite sheets are clearly ripped apart and the material is essentially defluorinated. EG is a low-density, black dust that can be easily temporality suspended in the air.

\section{Experimental}

Pure graphite dust (Aldrich Chemical, \#28286-3) and fluorinated graphite dust (Aldrich Chemical, \#37245-5) were used. A Mattson FT-IR spectrometer was utilized. Carbon-based compounds were put in a methanol slurry and dropped on IR cards and allowed to dry. Diffuse reflectance (DRIFT) and attenuated total reflectance (ATR) accessories were both tested, but sensitivity was inadequate. The Raman spectrometer is located in the laboratory of Professor Thomas Vickers and the Scanning electron Microscope and Transmission Electron Microscope are located in the Electron Microscope facility under the direction of Professor Ken Taylor located within the biology department at Florida State University.

The work described here is broken into three projects.

- The synthesis of exfoliated graphite and its subsequent transformation into nanotubular structures using $\mathrm{Fe}^{3+}$

- Synthesis of nanospheres of $\mathrm{C}_{1} \mathrm{~F}_{1}$ using a novel electrochemical cell

- Calorimetric studies of carbon-compounds combustion in the presence of $\mathrm{La}_{2} \mathrm{O}_{3}$.

In this laboratory, six students were broken into groups of two and rotated through each project.

It should be emphasized that the instructor should read many of the references listed to familiarize themselves with various aspects of the work. Details on previous experimental work or theoretical explanations for topics are lengthy and left to the citations provided. Throughout, the laboratory subtopics are presented to give the students a clearer image of the chemical and experimental parameters involved. For example, models of graphite and fluorinated graphite were constructed and discussed. A copper grid and an aluminum stud used for sample mounting in TEM and SEM, respectively, were shown and the sample analysis procedure explained.

\section{Synthesis}

Exfoliated Graphite. Synthesis of exfoliated graphite that is stable under ambient conditions can be accomplished using the following procedures:

Measure approximately 0.5 to $1.0 \mathrm{~g}$ of $\mathrm{C}_{1} \mathrm{~F}_{1}$ and record the sample mass. The density of the fluorinated graphite dust is calculated by measuring the sample volume using a graduated cylinder. The sample is then placed in a covered ceramic crucible. An IR is recorded on site and a small sample of $\mathrm{C}_{1} \mathrm{~F}_{1}$ is set aside for Raman and EM analysis. Figure 1 shows fluorinated graphite dust particles observed using SEM.

While heating the $\mathrm{C}_{1} \mathrm{~F}_{1}$ sample, flow argon $(10-50 \mathrm{~mL} / \mathrm{min})$ into the covered crucible to minimized combustion. Heat the sample with a Bunsen burner in a well-ventilated hood. Caution should be taken to avoid inhalation of the fluorine-based thermal decomposition products. Extinguish the Bunsen burner every 5-10 min and gently stir with a metal rod to ensure uniform heating of the sample.

After 60-90 min of heating, the gray fluorinated graphite should be converted to exfoliated graphite, a low-density carbon compound. The ceramic dish should be continuously monitored. Underheating will result in little or no thermal decomposition. Overheating will cause all of the fluorinated graphite dust to decompose. Figure $2 \mathrm{a}$ and $\mathrm{b}$ provides two images of the product. At this point, the compound should be relatively free of fluorine in any form. The students weigh the soot, measure its volume, and calculate the density of the product. A small quantity of this is set aside for transport to the SEM laboratory and the remainder will be used in Part $\mathrm{C}$ with a $\mathrm{Fe}^{3+}$ solution.

Production of Nanotubular Structures. Carbon nanotubes are typically produced in either a carbon-arc or a chemical-vapor deposition chamber. These specialized pieces of equipment are relegated to research laboratories and rarely incorporated in teaching laboratories; however, the following approach of synthesizing 5 to 12 $\mathrm{nm}$ diameter nanotubular structures (See Figure 3) can be conducted in most undergraduate laboratories.

Produce exfoliated graphite by thermal decomposition of $\mathrm{C}_{1} \mathrm{~F}_{1}$ in a ceramic dish (See Part A). This step should be conducted under a hood. 


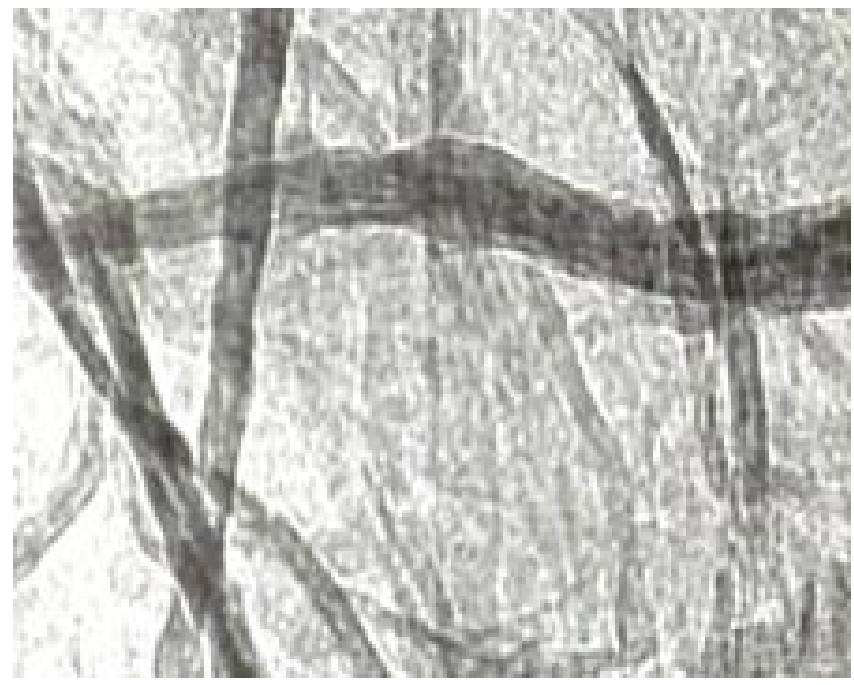

Figure 3. Exfoliated graphite treated with $\mathrm{Fe}^{+3}$ and heated to dryness produces solid nanotubular structures that range in diameter from 5 to 10 nanometers.

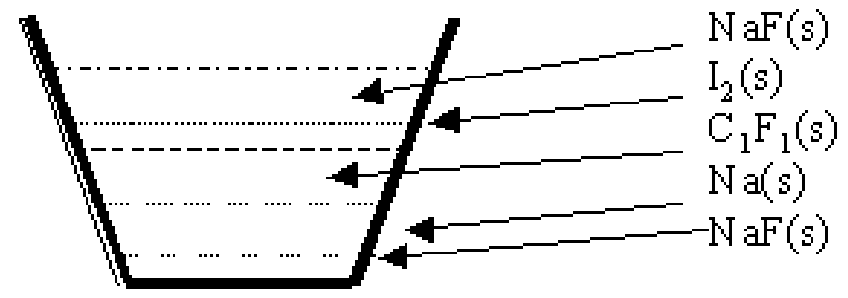

Figure 4. Synthesis \#1. (See Table 1.) Five layers ( $\mathrm{NaF}, \mathrm{Na}, \mathrm{C}_{1} \mathrm{~F}_{1}, \mathrm{I}_{2}$, $\mathrm{NaF}$ ) are pressed consecutively into a high temperature ceramic crucible.

Treat the EG dust with a $0.1 \mathrm{M} \mathrm{Fe}\left(\mathrm{NO}_{3}\right)_{3}$ in $1 \% \mathrm{HNO}_{3}$ so that the moles of $\mathrm{Fe}$ are at a 1:3 (Fe:C) ratio with the moles of carbon.

In an argon environment, gently heat the slurry with a Bunsen burner to complete dryness. Occasionally turn off the burner and stir the slurry/solid with a metal spatula. Do not overheat the mixture to avoid splattering. This simple synthesis will cause some of the graphite sheets to roll up into tubular bundles that are 5 to $12 \mathrm{~nm}$ in diameter (See Figure 3).

Production of $\mathbf{C}_{\mathbf{1}} \mathbf{F}_{\mathbf{1}}$ Nanospheres. In this laboratory we investigate a novel electrochemical approach to the production of fluorinated graphite nanospheres in a low temperature environment $(<$ $200{ }^{\circ} \mathrm{C}$ ). As in previous experiments, FT-IR, Raman, SEM, and TEM are used to qualitatively and quantitatively identify the starting material and the structures produced.

Seven crucibles were prepared and subjected to the conditions outlined in Table 1. The graphite dust $(1 \mu \mathrm{m})$ and fluorinated graphite dust $\left(\mathrm{C}_{1} \mathrm{~F}_{1}, 1-2 \mu \mathrm{m}\right.$ diameter) are trapped between layers of $\mathrm{Na}(\mathrm{s})$ and $\mathrm{I}_{2}(\mathrm{~s})$ in a ceramic crucible (See Figure 4). Students used 0.5 to 1.0 grams of $\mathrm{C}_{1} \mathrm{~F}_{1}$ (mass recorded exactly) and calculated the required mass of $\mathrm{I}_{2}$ and $\mathrm{Na}$ (s) if a 1:1:1 ratio of $\mathrm{Na}(\mathrm{s})$ to $\mathrm{C}$ to $\mathrm{I}$ is desired. In addition, the upper and lower layers of sodium fluoride allow gases formed by the reaction to escape and minimize air contamination of the electrochemical reaction.

Two ovens were used to heat each crucible for seven days. Each oven is set at a different temperature $\left(165{ }^{\circ} \mathrm{C}, 135{ }^{\circ} \mathrm{C}\right)$. The temperature is maintained above the melting points of $\mathrm{Na}(\mathrm{s})\left(98{ }^{\circ} \mathrm{C}\right)$ and $\mathrm{I}_{2}(\mathrm{~s})\left(114^{\circ} \mathrm{C}\right)$ but below the thermal decomposition temperature of fluorinated graphite $\left(450^{\circ} \mathrm{C}\right)$. Periodically check the sample.

The solid remaining in the crucible must be carefully washed with water to remove $\mathrm{NaF}$ and $\mathrm{Na}$ (s). Care must be taken to ensure no solid $\mathrm{Na}(\mathrm{s})$ is present that could react violently with water. The samples are then centrifuged and the water removed. The residual solid is heated at $110{ }^{\circ} \mathrm{C}$ to remove all trace amounts of water. The sample is then washed/soaked with hexane to remove any remaining $I_{2}(s)$. The sample is centrifuged and heated at $60{ }^{\circ} \mathrm{C}$ until completely dry. Analyze the sample by infrared spectroscopy and ship/store for imaging by SEM and TEM.

By using various controls, the students noted that it is only the ceramic dish with an electrochemical reaction that produces nanospheres of fluorinated graphite. At the prescribed temperatures $\left(165^{\circ} \mathrm{C}, 135^{\circ} \mathrm{C}\right)$, melted sodium and iodine will liquefy and permeate the $\mathrm{C}_{1} \mathrm{~F}_{1}$ layers allowing for the electrochemical reaction,

$$
\mathrm{Na}(\mathrm{s})+1 / 2 \mathrm{I}_{2}(\mathrm{~s}) \rightarrow \mathrm{NaI}(\mathrm{s})
$$

Our analysis of the control samples (See Table 1) by several electron microscopy techniques revealed essentially no change in the structure of the graphite or the fluorinated graphite. Through IR and Raman spectroscopy, a strong C-F peak $\left(1210 \mathrm{~cm}^{-1}\right)$ indicated no thermal decomposition of the fluorinated graphite controls occurred and that the nanospheres observed via TEM were $\mathrm{C}_{1} \mathrm{~F}_{1}$ (See Figures 5 and 6).

\section{Thermodynamics}

As discussed in the introduction, lanthanum has been shown to play a role in the production of fullerenes, nanotubes, and lanthanum carbide nanoparticles. Lanthanum was one of the first metals to be used in making of endohedral fullerene and metal carbide nanostructures. These lanthanum compounds have been found to be unusually stable due to the delocalization of the La electrons about the carbon skeleton.

In this part of the laboratory we chose to investigate whether or not we could detect any thermodynamic evidence of $\mathrm{La}_{2} \mathrm{O}_{3}$ affecting the combustion of graphite or fluorinated graphite. Benzoic acid was used to determine the calorimeter constant. The gas-phase combustion products of each trial were trapped in a $10-\mathrm{cm}$ quartz cell and qualitatively identified by FT-IR. The following reactions are pertinent to the experiment:

$$
\mathrm{C}(\text { graphite })+\mathrm{O}_{2}(\mathrm{~g}) \rightarrow \mathrm{CO}_{2}(\mathrm{~g}) \quad \Delta H_{\mathrm{rxn}}=-393.51 \mathrm{~kJ} \mathrm{~mol}^{-1}
$$

$4 \mathrm{C}_{1} \mathrm{~F}_{1}(\mathrm{~s})+3 \mathrm{O}_{2}(\mathrm{~g}) \rightarrow 3 \mathrm{CO}_{2}(\mathrm{~g})+\mathrm{CF}_{4}(\mathrm{~g}) \quad \Delta H_{\mathrm{rxn}}=-102 \mathrm{~kJ} \mathrm{~mol}^{-1}$

From our discussion we felt the formation of nanospheres of $\mathrm{La}_{\mathrm{x}} \mathrm{C}_{\mathrm{y}}$ was more likely (as opposed to fullerene or nanotube formation) and the students were asked to make arguments, based on bond energies, as to whether they would observe an increased, decreased, or constant enthalpy of combustion. Appendix A provides some discussion of nanoparticles and contains references for additional reading.

Ten combustion reactions were measured over two laboratory periods. These are listed in Table 2 . The results (time versus temperature) are illustrated in Figures 8 and 9.

The heat of combustion calculated from bond energies of pure graphite (eq 1) was determined to be $-393.51 \mathrm{~kJ} \mathrm{~mol}^{-1}$. Pure graphite dust's experimental $\Delta H$ value was determined experimentally to be $-378.370 \mathrm{~kJ} \mathrm{~mol}^{-1}$ and $-381.579 \mathrm{~kJ} \mathrm{~mol}^{-1}$ for trials 1 and trial 2, respectively, with an average $\Delta H$ of $379.975 \mathrm{~kJ} \mathrm{~mol}^{-1}$. The values of the graphite and $\mathrm{La}_{2} \mathrm{O}_{3}$ graphite were statistically the same. A similar result was 
Table 1. Contents, Temperature, Duration, and Purpose for Seven Crucibles Set Up the First Week, Heated in the Oven for Seven Days, and Disassembled and Analyzed by IR, Raman, SEM and TEM

\begin{tabular}{|c|c|}
\hline $\begin{array}{l}\text { Crucible Contents } \\
\text { (from top to bottom) }\end{array}$ & Temperature, Duration, Purpose \\
\hline \multicolumn{2}{|l|}{ Control \#1. } \\
\hline $\mathrm{NaF}(\mathrm{s})$, Graphite, $\mathrm{NaF}(\mathrm{s})$ & $165^{\circ} \mathrm{C}, 7$ days, Control to test effects of temperature on graphite dust \\
\hline Control \#2 & \\
\hline $\mathrm{NaF}(\mathrm{s})$, fluorinated graphite, $\mathrm{NaF}(\mathrm{s})$ & $165^{\circ} \mathrm{C}, 7$ days, Control to test effects of temperature on fluorinated graphite dust \\
\hline Control \#3 & \\
\hline $\begin{array}{l}\mathrm{NaF}(\mathrm{s}), \mathrm{I}_{2}(\mathrm{~s}) \text {, fluorinated graphite, } \mathrm{NaF}(\mathrm{s}) \\
\text { Control } \# 4\end{array}$ & $165^{\circ} \mathrm{C}, 7$ days, Control to test effects of temperature and $\mathrm{I}_{2}$ on fluorinated graphite dust \\
\hline $\begin{array}{l}\mathrm{NaF}(\mathrm{s}) \text {, fluorinated graphite, } \mathrm{Na}(\mathrm{s}), \mathrm{NaF}(\mathrm{s}) \\
\text { Control \#5 }\end{array}$ & $165^{\circ} \mathrm{C}, 7$ days, Control to test effects of temperature and $\mathrm{Na}(\mathrm{s})$ on fluorinated graphite dust \\
\hline $\begin{array}{l}\mathrm{NaF}(\mathrm{s}), \mathrm{I}_{2}(\mathrm{~s}) \text {, graphite, } \mathrm{Na}(\mathrm{s}), \mathrm{NaF}(\mathrm{s}) \\
\text { Synthesis } \# 1\end{array}$ & $165^{\circ} \mathrm{C}, 7$ days, Control to test effects of temperature, $\mathrm{I}_{2}$, and $\mathrm{Na}(\mathrm{s})$ on graphite dust \\
\hline $\begin{array}{l}\mathrm{NaF}(\mathrm{s}), \mathrm{I}_{2}(\mathrm{~s}) \text {, fluorinated graphite, } \mathrm{Na}(\mathrm{s}), \mathrm{NaF}(\mathrm{s}) \\
\text { Synthesis } \# 2\end{array}$ & $165^{\circ} \mathrm{C}, 7$ days, Electrochemical synthesis to convert on fluorinated graphite \\
\hline $\mathrm{NaF}(\mathrm{s}), \mathrm{I}_{2}(\mathrm{~s})$, fluorinated graphite, $\mathrm{Na}(\mathrm{s}), \mathrm{NaF}(\mathrm{s})$ & $\begin{array}{l}135^{\circ} \mathrm{C}, 7 \text { days, Synthesis to test effects of a lower temperature on the electrochemical synthesis } \\
\text { of fluorinated graphite }\end{array}$ \\
\hline
\end{tabular}

Table 2. Ten Combustion Reactions Measured over Two Laboratory Periods

\begin{tabular}{ll}
\hline Combustion material & Comment \\
\hline $1.0 \mathrm{~g}$ benzoic acid & Used to determine calorimeter constant $(2$ trials $)$ \\
$1.0 \mathrm{~g}$ graphite dust & Produced only $\mathrm{CO}_{2}(\mathrm{~g})(2$ trials $)$ \\
$1.0 \mathrm{~g}$ fluorinated graphite & Produces $\mathrm{CO}_{2}$ and $\mathrm{C}_{\mathrm{x}} \mathrm{F}_{\mathrm{y}}(\mathrm{g})$ compounds $(2$ trials $)$ \\
$0.5 \mathrm{~g}$ graphite dust and $0.5 \mathrm{~g}$ fluorinated graphite & Produces $\mathrm{CO}_{2}, \mathrm{C}_{\mathrm{x}} \mathrm{F}_{\mathrm{y}}(\mathrm{g})$ and $\mathrm{C}_{\mathrm{x}} \mathrm{H}_{\mathrm{y}}(\mathrm{g})(2$ trials $)$ \\
$0.9 \mathrm{~g}$ fluorinated graphite and $0.1 \mathrm{~g} \mathrm{La}_{2} \mathrm{O}_{3}(\mathrm{~s})$ & Produces $\mathrm{CO}_{2}$ and $\mathrm{C}_{\mathrm{x}} \mathrm{F}_{\mathrm{y}}(\mathrm{g})$ compounds $(1$ trial $)$ \\
$0.9 \mathrm{~g}$ graphite and $0.1 \mathrm{~g} \mathrm{La}_{2} \mathrm{O}_{3}(\mathrm{~s})$ & Produces $\mathrm{CO}_{2}(\mathrm{~g})$ determined by IR $(1$ trial $)$ \\
\hline
\end{tabular}
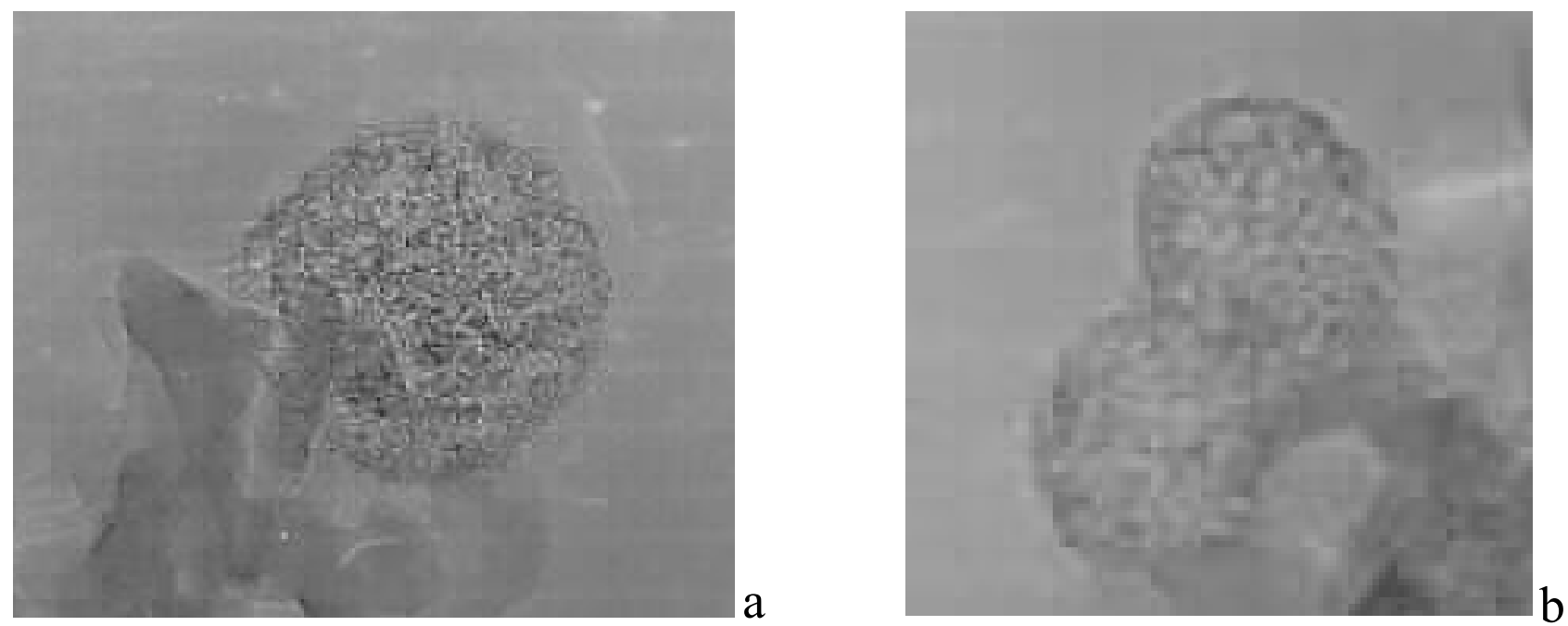

Figure 5. a. TEM image of a nanosphere (12 nm diameter) of fluorinated graphite produced in the simple synthesis \#2 (Table 1). B.Two 8-10 nm nanospheres bound together. IR and Raman spectroscopy were used to confirm that no appreciable thermal decomposition took place and the nanospheres are fluorinated graphite

obtained when the fluorinated graphite and Lanthanum mix was burned. Figure 8 illustrates FT-IR spectra for $\mathrm{CO}_{2}(\mathrm{~g})$ recorded from the combustion products of pure graphite; Figure 9 illustrates the IR spectra $\left(\mathrm{CO}_{2}\right.$ and molecular species containing $\mathrm{C}-\mathrm{F}$ bonds) for the combustion of fluorinated graphite. Figure 10 is experimental calorimetric data for the graphite-dust combustion. Figure 11 is experimental calorimetric data for the $\mathrm{C}_{1} \mathrm{~F}_{1}$ combustion.

\section{Schedule}

Session 1. Each student gave a five-minute oral presentation about a technical paper (for example, see references 1, 6, 9, 13-15) provided the previous week. The use of the bomb calorimeter was reviewed and the sample preparation for the electrochemical cell was outlined. Two students started working with the bomb calorimeter, two students prepared the exfoliated graphite, and two students set up the electrochemical cells and placed them in the ovens. One of the students prepared the EG ran the FT-IR of graphite dust, 


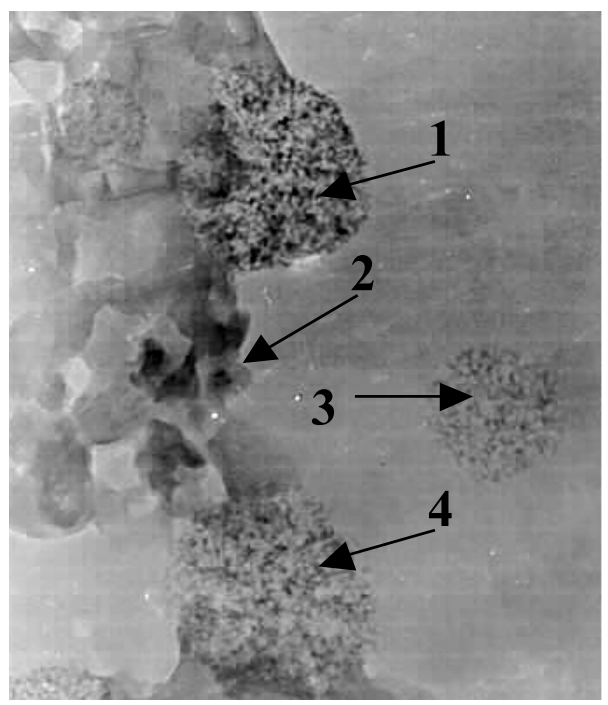

Figure 6. Several 5-14-nm diameter fluorinated graphite nanospheres $(1,3$, and 4$)$ are captured in this TEM image. The other globular materials (2) are referred to as carbon aerogels.
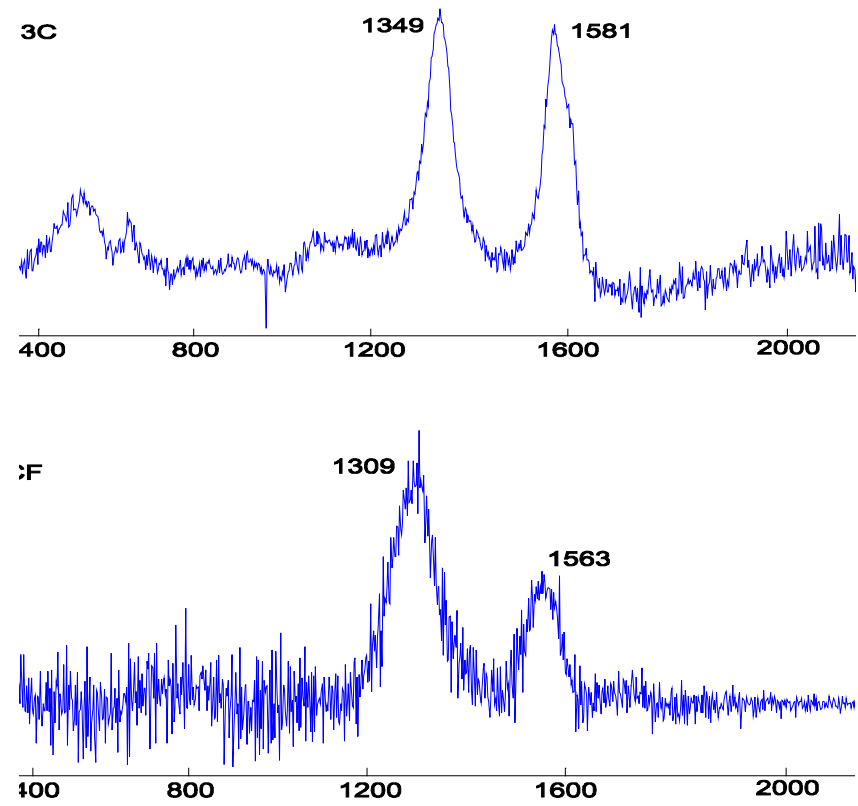

G

1574

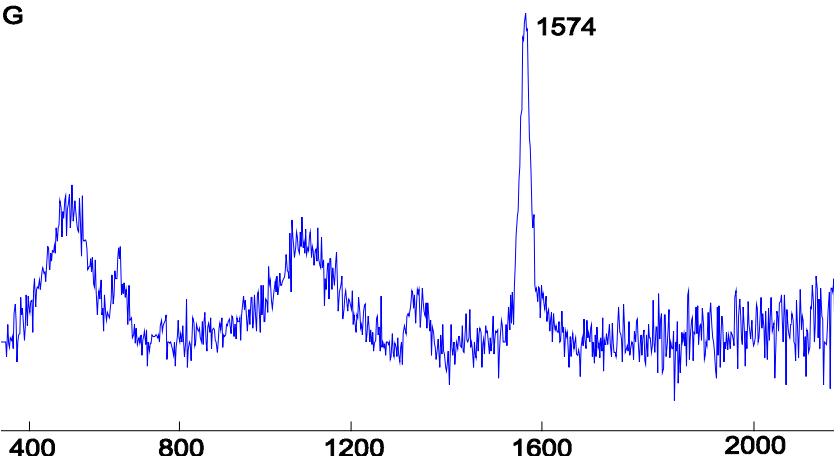

Figure 7. Raman spectra of treated fluorinated-graphite-containing nanospheres (top), spectra of fluorinated graphite dust that was the starting material (middle) and pure graphite dust (bottom) that was used in some of the controls outlined in Table 1. This data, along with the IR, demonstrated that the fluorinated graphite did not thermally decompose into graphite; however, wavenumber shifts indicate changes did take place. The $\mathrm{x}$ axis is in wavenumbers and the $\mathrm{y}$ axis is the intensity of the laser scatter.

fluorinated graphite dust, and EG. The density of graphite dust, fluorinated graphite, and EG were also measured.

Session 2. Each student gave a 5 to 7 minute talk at the beginning of the laboratory concerning an analysis technique (Raman, SEM, TEM) or a material (GICs, fullerenes, nanoencapsulates) as assigned the previous week. The groups of two were rotated so that different students continued work on the bomb calorimeter, treated the EG produced in session 1 with $\mathrm{Fe}^{+3}$, and disassembled the electrochemical cells. At the end of the laboratory, two packets of each of the nine samples (EG, EG treated with $\mathrm{Fe}^{+3}$, and the seven carbon samples outlined in Table 1) were shipped to the Raman spectroscopy laboratory and the EM laboratory. FT-IR of the nine samples was taken and the spectra distributed to all students.

Session 3. When the Raman spectra and SEM and TEM images were returned (approximately one month after session 2 ), session 3 was convened. Students gave five-minute presentations using visual aids on papers and Websites assigned the previous laboratory period. Topics included hydrogen storage, $\mathrm{H}_{2} / \mathrm{O}_{2}$ combustion engines, $\mathrm{H}_{2} / \mathrm{O}_{2}$ electrochemical cells, $\mathrm{LaC}$ nanoencapsulates, $\mathrm{BN}$ nanostructures, and nanotechnology involving DNA. Students assembled all of the data (density, IR, Raman, SEM, TEM, and $\left.\Delta H_{\text {combustion }}\right)$ and spent the remainder of the laboratory period discussing and correlating thermodynamic, vibrational, and electron microscopy data with the instructor. The primary focus was clearly the images of what was produced at the nanometer level. In addition to interpreting and correlating different data sets, students began to organize data for their final laboratory report.

\section{Questions included in the laboratory}

Exfoliated graphite: 1) What is a van der Waals force and what role does it play in holding graphite together?

2) Its been proposed that $\mathrm{H}_{2}$ can be stored in nanotubes and used as a battery. Discuss how the EG you produced might work in this application. Specifically, outline the electrochemical reaction involving hydrogen and oxygen, compare it with the combustion reaction of hydrogen and oxygen, and propose a simple schematic for how a $\mathrm{H}_{2} / \mathrm{O}_{2}$ battery might work.

3) Briefly discuss how hydrogen $\left(\mathrm{H}_{2}\right)$ would absorb on the surface of a carbon nanotube (forces involved, potential geometries, etc.).

4) Compare the IR, Raman, density, SEM, and TEM data of the EG with that of graphite and fluorinated graphite.

Electrochemical cell: 1) What is $E_{\text {cell }}^{\mathrm{o}}$ for the sodiumiodine reaction at $25^{\circ} \mathrm{C}$ ? Assume enthalpy and entropy for the reaction are constant, what is the Gibbs free energy at $75^{\circ} \mathrm{C}$ ?

2) Will iodine replace fluorine in $\mathrm{C}_{1} \mathrm{~F}_{1}$ and make $\mathrm{C}_{1} \mathrm{I}_{1}$ ? Will $\mathrm{Na}$ (atom, ion) bind carbon? Will $\mathrm{NaF}$ or $\mathrm{NaI}$ be the preferred product? Use thermodynamics to support your argument.

3) If a fluorinated graphite sphere $\left(\mathrm{C}_{1} \mathrm{~F}_{1}\right)$ has a $20-\mathrm{nm}$ diameter and a density of $2 \mathrm{~g} \mathrm{~cm}^{-3}$, how many carbon and fluorine atoms are contained in that volume. Compare the IR, Raman, density, SEM, and TEM data. 
Table 3. Heats of combustion obtained with an oxygen-filled bomb calorimeter

\begin{tabular}{lc}
\hline Compound & Enthalpy $\left(\mathrm{J} \mathrm{g}^{-1}\right)$ \\
\hline Graphite $(1 \mathrm{~g}$, trial 1$)$ & $-31,501.99$ \\
Graphite $(1 \mathrm{~g}$, trial 2$)$ & $-31,769.13$ \\
Fluorinated graphite $(1 \mathrm{~g}$, trial 1) & $-11,842.12$ \\
Fluorinated graphite $(1 \mathrm{~g}$, trial 2$)$ & $-11,713.15$ \\
Graphite $(0.9$ grams $), \mathrm{La}_{2} \mathrm{O}_{3}(0.1 \mathrm{~g})$ & $-31,280.01$ \\
Fluorinated graphite $(0.9 \mathrm{~g}), \mathrm{La}_{2} \mathrm{O}_{3}(0.1 \mathrm{~g})$ & $-12,800.56$ \\
\hline
\end{tabular}

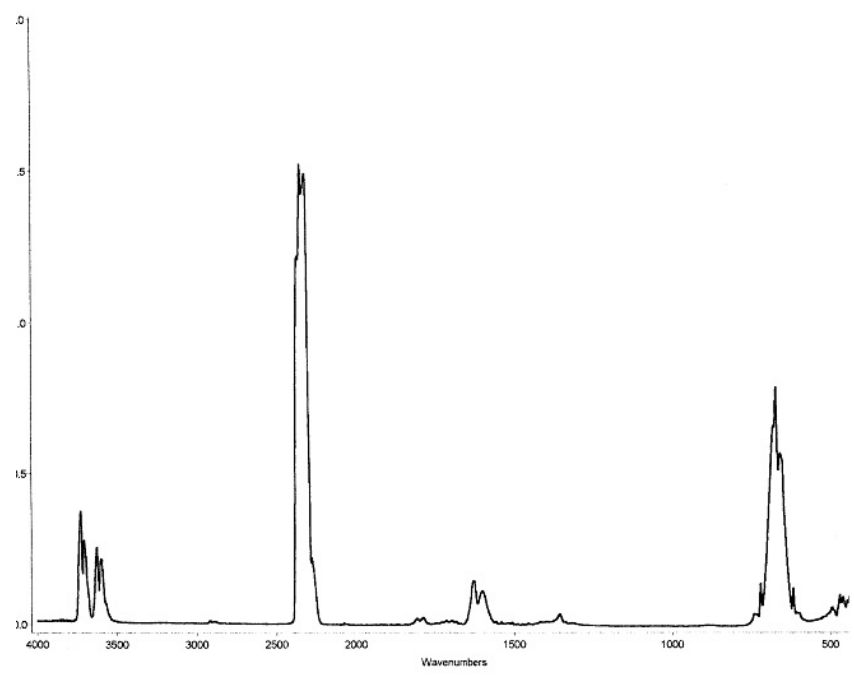

Figure 8. FT-IR spectra of the $\mathrm{CO}_{2}(\mathrm{~g})$ in a $10-\mathrm{cm}$ quartz cell. $\mathrm{CO}_{2}$ is the primary combustion products of graphite dust.

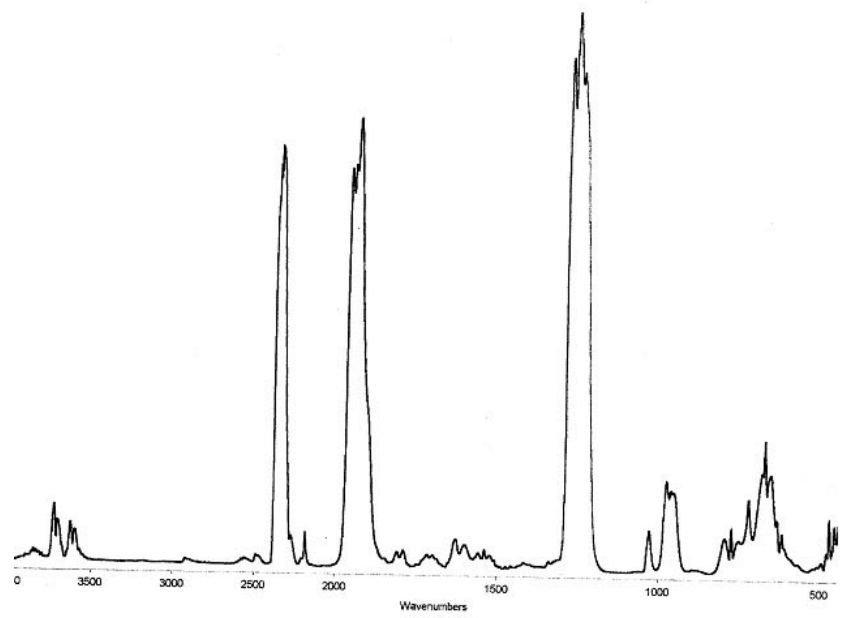

Figure 9. Infrared spectra of the gas-phase combustion products of fluorinated graphite dust (i.e., $\mathrm{CO}_{2}, \mathrm{C}_{\mathrm{x}} \mathrm{F}_{\mathrm{y}}(\mathrm{g})$, etc.). The intense peak at $1210 \mathrm{~cm}^{-1}$ is the result of a $\mathrm{C}-\mathrm{F}$ bond.

Bomb Calorimeter: 1) What effect did the lanthanum have on the combustion of graphite? fluorinated graphite?

2) Calculate the heat of combustion of graphite from bond energies and compare this with the value you measured.

3) Why is the heat of combustion for fluorinated graphite lower than graphite? Use bond energies to explain your answer.

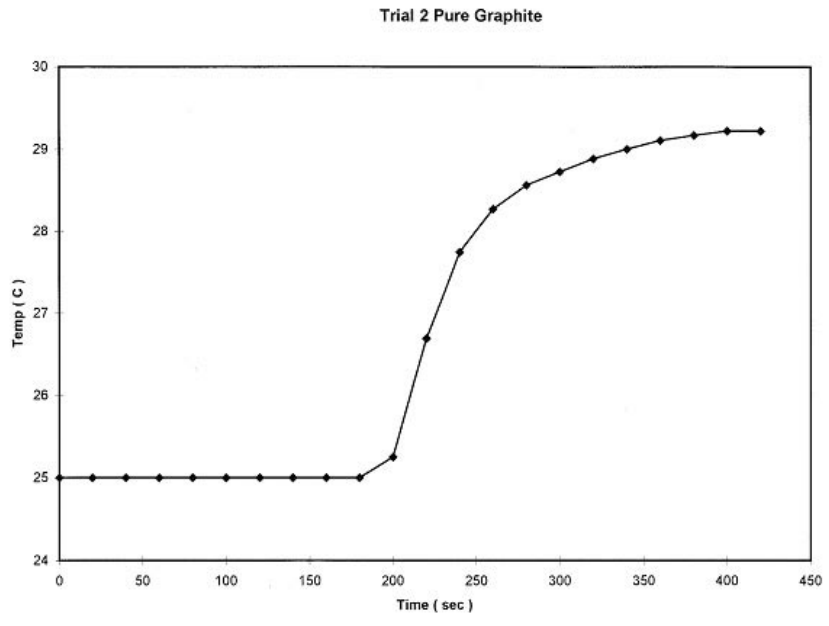

Figure 10. Calorimetric $\Delta T$ data recorded for the combustion of pure graphite dust in a bomb calorimeter.

\section{Conclusion}

While nanotechnology has been a rapidly growing area of science, there are few published laboratories for the undergraduate chemistry curriculum, and a majority of those are concerned with $\mathrm{C}_{60}$ [51-58]. From our exploratory work, a range of other experiments and computer simulations can be developed or tested including

Exfoliated graphite and nanotubular structures. Using the same procedure described above, try other metals than $\mathrm{Fe}^{+3}$ (e.g., $\mathrm{La}^{+3}, \mathrm{Co}^{+2}, \mathrm{Ni}^{+2}, \mathrm{Ca}^{+2}, \mathrm{Sr}^{+2}$ ) that have shown influence on nanostructure formation. Also, test other metals and metalloids that might potentially produce interesting carbide chemistry (W, Si, etc.) and search for nanostructures.

Calorimetry. Test different ratios of $\mathrm{La}_{2} \mathrm{O}_{3}(1: 1$ by mass and by atom ratio) with graphite and fluorinated graphite. Experiment with different metal salts containing nickel, iron, cobalt, calcium, or strontium at different ratios. Show fullerene production in the flames of hydrocarbons (i.e., benzene), combustion with and without the metal salts previously mentioned. Soak graphite and fluorinated graphite in solutions of $\mathrm{La}^{3+}, \mathrm{Fe}^{3+}, \mathrm{Ni}^{2+}, \mathrm{Co}^{2+}, \mathrm{Ca}^{2+}$, or $\mathrm{Sr}^{2+}$ to adsorb cations, gently drying the mixture. Take graphite and fluorinated graphite through the same procedure as the controls (soak in just a matching acid solution). After compounds are completely dried, use them for combustion reactions. Treat EG as described with any of the metals (including the heating stage), thoroughly dry and attempt combustion of the solid. any of these have been shown to form nanostructures (i.e., $\mathrm{CaC}_{2}$, $\mathrm{Fe}_{3} \mathrm{C}$, etc.).

Electrochemical cell. Instead of using $\mathrm{Na}(\mathrm{s})$, try a metal $(\mathrm{K}$, $\mathrm{Rb}, \mathrm{Cs}$ ) with a lower ionization potential and a lower boiling point. Try $\mathrm{Br}_{2}(\mathrm{l})$ instead of $\mathrm{I}_{2}$. For example, Cs metal (bp $=29$ ${ }^{\circ} \mathrm{C}$ ) could be embedded with fluorinated graphite dust by gentle heating and mixing in an inert gas environment. It would solidify at room temperature $\left(25^{\circ} \mathrm{C}\right)$. React these mixtures with $\mathrm{Br}_{2}(1)$ under carefully controlled conditions. Perhaps some of these reactions will take a shorter period of time, run at lower temperatures, or produce more nanospheres with a different electrochemical reaction $\left(E_{\text {cell }}^{\mathrm{o}}\right.$ varies $)$.

Computer Simulations. A range of molecular modeling programs are available that can be used in an undergraduate 
laboratory. When this laboratory is completed, students have a deeper understanding of carbon structures and could be given exercises to simulate hydrogen $\left(\mathrm{H}_{2}\right)$ adsorption on graphite, construct spherical and tubular structures based on carbon and boron nitride, and simulate small metal-carbide structures.

Collaborations between four year undergraduate programs and research I programs can be productive for all parties involved. Exploratory laboratories are unique experiences that straddle the line between pure research and teaching focusing faculty and students, on current topics and techniques. Sutents gain first hand experience working with faculty, staff and equipment and have an increased interest in graduate school.

\section{Appendix A: Review of Nanotubes, Graphite-Intercalated Compounds, Boron Nitrides, Etc.}

Boron Nitride and Silicon. The syntheses of nanometersized components have extended beyond carbon $[2,10,16-$ 20]. A drawback to the utilization of carbon nanotubes, based on conductivity, is the inability to control the chirality. Boron nitride (BN) nanotubes, however, have conductive properties that are independent of chirality, diameter, and even the number of walls in the tube. BN nanotubes have been doped to optimize their conductivity for uses in molecular electronic devices and can be synthesized by several methods, depending on the desired properties and yields. Tubes as long as $40 \mu \mathrm{m}$ can be constructed by continuous laser heating, or smaller tubes can be created via carbon substitution. Overheating in nanoelectronics is of major concern, and the nonreactive BN tubes are better-suited for these environments. Boron nitride tubes should also be more durable than their carbon counterparts, allowing for increased utilization in a variety of fields.

Reducing the size in silicon-based nanotechnology is also a major endeavor of scientific and electronic research [16]. Actual contact between carbon nanotubes and silicon substrates has been achieved via heat treatment. Heating forms a solid-state reaction in the regions between the nanotubes in contact with the silicon. This reaction forms rod-shaped SiC. Leaders in computer technology innovation are investigating the potential semiconducting properties of this structure. Silicon nanowires may also alter the future operation of electronic devices. To increase speed and reduce the energy use associated with electrical conductivity, engineers are pushing to synthesize electronic devices smaller and more complex. Silicon nanowires, which are etched from bulk silicon, are constructed of clusters containing 24 silicon atoms and attached to aluminum leads. Because the clusters form hollow cages, similar to the carbon nanotubes, they could be constructed containing a dopant atom. This approach should increase device consistency.

Nanoparticles. All areas of science have embraced nanoparticles [2, 6-8, 21-23]. In chemistry synthesis, characterization, and applications of derivative forms of buckyballs and nanotubes have been explored extensively [11, 12]. Nanoencapsulates, nanoparticles, and nanospheres are terms that are used to describe small particles that are metal (i.e., $\mathrm{Cu}$ ) or metal-carbides (i.e., $\mathrm{Fe}_{3} \mathrm{C}$ ). For example, Takeda [17] measured the optical properties, including nonlinear susceptibility and response for insulators with embedded nanoparticles fabricated by ion implantation. Oku [18] synthesized gold nanoparticles and nanowires in carbon nanocapsules and nanotubes that spontaneously formed from one-dimensional self-organized gold nanoparticles on carbon thin films by annealing at low temperatures of $200-400{ }^{\circ} \mathrm{C}$. The one-dimensional arrangement of gold nanoparticles was found to be strongly dependent on the adhesive force at the atomic step edges of amorphous carbon thin films. The gold crystals inside the nanotubes are distorted by the crystal growth of the nanowires. Poly(2-methoxy-5-ethylhexyloxy1,4-phenylene vinylene) (MEH-PPV)/rutile- $\mathrm{TiO}_{2}$ composite films were made by Kim [19] with various sizes from 7 to 23 $\mathrm{nm}$ and their electroluminescent characteristics were investigated. Barnes [20] investigated the perturbing influence of nanosize filler particles on the dewetting of spun-cast polymer films. Rotkin [21] developed a new heuristic model for the calculation of the formation energy of the carbon nanoclusters.

Saito [22] generated a rectangular parallelopiped (or cube) form of graphitic cages in nanometer scale. They were produced by evaporation of a carbon electrode containing calcium or strontium. Both the empty and the filled rectangular nanocapsules, averaging 20 to $100 \mathrm{~nm}$ in size, were formed; however, empty rectangular nanocapsules were dominant. The rectangular cages were made up of multiwalled (5-20 layers) graphitic carbon. The encapsulated materials were $\beta$ $\mathrm{CaC}_{2}$ (tetragonal), $\gamma-\mathrm{CaC}_{2}$ (cubic) and $\delta-\mathrm{CaC}_{2}$ (monoclinic) for $\mathrm{C} / \mathrm{Ca}$ evaporation, and $\beta-\mathrm{SrC}_{2}$ (tetragonal) and metallic $\mathrm{Sr}$ for $\mathrm{C} / \mathrm{S}$ revaporation.

Liu and Crowely [23] produced structures of manganesefilled carbon nanotubes and nanoparticles using an arcdischarge method by using a composite anode. These were examined with high-resolution transmission electron microscopy (HRTEM), selected-area electron diffraction, and electron nanodiffraction techniques. The HRTEM images and corresponding diffraction patterns show that various manganese carbides $\left(\mathrm{Mn}_{3} \mathrm{C}, \mathrm{Mn}_{5} \mathrm{C}_{2}, \mathrm{Mn}_{7} \mathrm{C}_{3}\right.$, and $\left.\mathrm{Mn}_{23} \mathrm{C}_{6}\right)$ were formed within nanotubes and nanoparticles. Most encapsulated Mn carbides appeared as perfect single nanocrystals.

Single-domain microcrystals of $\mathrm{LaC}_{2}$ encapsulated within nanoscale polyhedral carbon particles have been synthesized in a carbon arc by Liu and Crowely [23]. Typical particle sizes are on the order of 20 to 40 nanometers. The stoichiometry and phase of the La-containing crystals have been assigned from characteristic lattice spacings observed by high-resolution transmission electron microscopy and energy dispersive spectroscopy (EDS). EDS spectra show that La and $\mathrm{C}$ are the only elements present. Characteristic interatomic distances of 3.39 and $2.78 \AA$ identify the compound inside the nanoparticle cavities as $\alpha-\mathrm{LaC}_{2}$, the phase of $\mathrm{LaC}_{2}$ that is stable at room temperature. Bulk $\alpha-\mathrm{LaC}_{2}$ is metallic and hydrolytic. Observation of crystals of pure encapsulated $\alpha-\mathrm{LaC}_{2}$ that were exposed to air for several days before analysis indicate that the $\mathrm{LaC}_{2}$ is protected from degradation by the carbon polyhedral shells of the nanoparticles. A high percentage of the carbon nanoparticles have encapsulated $\mathrm{LaC}_{2}$ single crystals. These carbon-coated metal crystals were described as a new class of materials that can be protected in their pure or carbide forms and may have interesting and useful properties.

Exfoliated Graphite and GICs. In a previous paper [50], we showed that the covalently bonded graphite-intercalation compound fluorinated graphite $\left(\mathrm{C}_{1} \mathrm{~F}_{1}\right)$ forms exfoliated graphite (EG) when processed in an atmospheric pressure 
27.12 $\mathrm{MHz}$ inductively coupled argon plasma. This EG differed from other EG produced [25-44] in that the ends of the graphitic sheets were rolled or formed tubes. The micronsized carbon dust produced by this process has a low density $\left(0.013 \mathrm{~g} \mathrm{~cm}^{-3}\right)$, high surface area $\left(150 \mathrm{~m}^{2} \mathrm{~g}^{-1}\right)$, minimum impurities (99.5\% \pm Carbon), honey-combed structure (SEM pictures), and tubular endings $\left(1345 \mathrm{~cm}^{-1}, 1590 \mathrm{~cm}^{-1}, 1620\right.$ $\mathrm{cm}^{-1}$, Raman Spectroscopy) [24]. Subsequent work has demonstrated that $\mathrm{C}_{1} \mathrm{~F}_{1}$ easily decomposes to a collapsible form of $\mathrm{EG}$ when heated in a covered ceramic disk with flowing argon to minimize combustion.

The industrial production of fluorinated-graphite $\left(\mathrm{C}_{n} \mathrm{~F}_{n} ; n=\right.$ 1) compounds is carried out at high temperatures $\left(600^{\circ} \mathrm{C}\right)$ by reacting graphite with $\mathrm{F}_{2}$ gas for several hours [27]. Fluorinegraphite intercalation compounds, which are nonconductors, have an experimental density of $0.64 \mathrm{~g} \mathrm{~cm}^{-3}$, a surface area of $218 \mathrm{~m}^{2} \mathrm{~g}^{-1}$, and thermally decomposes at $450{ }^{\circ} \mathrm{C}$. Brominated graphite is easily synthesized by reacting graphite with $\mathrm{Br}_{2}$ liquid or vapor at room temperature and pressure and it has a reversible intercalation-deintercalation process. When the brominated graphite compound is heated above a critical temperature, it puffs up or becomes exfoliated. When the process is reversed, there exists a residual bromine component in the graphite complex. How much bromine is left is dependent on the original particle size, temperatures, etc. For this laboratory, we sought a final product free of most impurities and preferably $100 \%$ carbon, minimizing the use of brominated-graphite.

Scientists have conducted extensive work with the graphiteintercalated compounds $\mathrm{Br}_{2}, \mathrm{ICl}$, and $\mathrm{HNO}_{3}$ and demonstrated that the exfoliation or puffing of the structure takes place above $170{ }^{\circ} \mathrm{C}, 190{ }^{\circ} \mathrm{C}$, and $130{ }^{\circ} \mathrm{C}$, respectively [27. 28]. The $\mathrm{Br}_{2}$ GIC and ICl GIC collapse when cooled below $100{ }^{\circ} \mathrm{C} / 210$ ${ }^{\circ} \mathrm{C}$ and $190{ }^{\circ} \mathrm{C}$, respectively. The $\mathrm{Br}_{2}$ GIC's collapse temperature varies with the starting material (HOPG, singlecrystal graphite, respectively). Mazieres et al. [29, 30] observed that $\mathrm{Br}_{2}-$ graphite on pyrocarbons underwent first exfoliation at $200{ }^{\circ} \mathrm{C}$ and collapsed at $100{ }^{\circ} \mathrm{C}$ when cooled. Mazieres et al. [30] observed irreversible exfoliation after heating brominated graphite on pyrocarbons to $1000{ }^{\circ} \mathrm{C}$ and cooling the compound in an argon atmosphere. Exfoliated graphite can be synthesized by mixing and decomposing graphite-intercalation compounds with various acids. For example EG can be produced from reactions involving $\mathrm{HNO}_{3} / \mathrm{H}_{2} \mathrm{SO}_{4}, \mathrm{FeCl}_{3} / \mathrm{NH}_{3}$, and $\mathrm{AlCl}_{3}$ [31-33]. Other methods, not using acids, such as the heating of potassium-graphitetetrahydrofuran ternary compounds $\left(\mathrm{KC}_{24}(\mathrm{THF})_{1}\right.$ and $\mathrm{KC}_{24}(\mathrm{THF})_{2}$ ), have also been used to produce EG [34]. These methods can be time consuming in that they require an initial synthesis of a specific graphite-intercalation compound, the conversion of the GIC to the exfoliated graphite, and a residue such a metal ion or an acid removed from the EG by additional washing or heating. Exfoliated graphite (EG), which has several industrial applications, has been used in numerous chemical and nuclear plants as sealing materials under the name of Grafoil [35, 36]. Flexibility and elasticity characteristics, high thermal resistance, high chemical stability, and light weight characterize Grafoil.

Another form of pure carbon that has an open pore structure is reticulated vitreous carbon (RVC) [40. 44]. It has a large, honeycomb structure with 10 to 100 pores per inch. The pores in those structures are approximately 1000 times larger than those reported here and they have a large $\left(500 \mathrm{~m}^{2} \mathrm{~g}^{-1}\right)$ surface area and a low density $\left(0.048 \mathrm{~g} \mathrm{~cm}^{-3}\right)$. This material has the appearance of fused carbon whiskers and has reported impurities of $\mathrm{N}, \mathrm{H}, \mathrm{Fe}, \mathrm{Cu}, \mathrm{Al}$, or $\mathrm{Mg}$. A range of applications have been found for this material including electrode material, filtration, and high temperature insulation.

Hydrogen Storage in Nanotubes. Hydrogen and oxygen can produce energy by combustion or via an electrochemical reaction. While oxygen is plentiful in the atmosphere, an economical and practical method of hydrogen storage has long been sought. With the discovery of carbon nanotubes, there have been theoretical and experimental investigations into using carbon nanotubes to store hydrogen gas [45-47]. Jorissen et al. [45] investigated hydrogen adsorption on carbon materials at 25 bar and $23{ }^{\circ} \mathrm{C}$ and achieved values of $1.5 \mathrm{wt} \%$. Bauschlicher [46] modeled the addition of $\mathrm{H}$ and $\mathrm{F}$ to the side of a carbon nanotube. Zuttel et al. [47] showed that carbon nanotubes can electrochemically store relatively large amounts $(110 \mathrm{mAh} / \mathrm{g})$ of hydrogen and the reaction is highly reversible. The nanotube storage device is used to produce electrodes for rechargeable batteries.

\section{References and Notes}

1. Kroto, H. W.; Heath, J.; O'Brien, S.; Curl, R.; and Smalley, R. Nature 1985, 318, 162-163.

2. Dresselhaus, M. S.; Dresselhaus, G.; Eklund, P. Science of Fullerenes and Carbon Nanotubes; Academic Press: London, 1996; Kratschmer, W.; Lamb, L.; Fostiropoulos, K.; Huffman, D.; Nature 1990, 347, 354-358.

3. Ebbesen, T. W. Annu. Rev. Mater. Sci. 1994, 24, 235-273.

4. Ge, M.; Sattler, K.; Science 1993, 260, 515-518.

5. Cook, J.; Sloan, J.; Green, M. Chemistry and Industry, Aug 19, 1996, 600-601.

6. Nanotechnology - Tube Turnaround. Chemistry \& Industry, March 20, 2000, 200.

7. National Nanotechnology Initiative. Anal. Chem. 2000, 72 (5), A189.

8. Nanotechnology - Molecular Movement Makes Miniature Motors. Chemistry \& Industry, Sept 20, 1999, 689-690.

9. Tolles, W. M. Nanoscience and Nanotechnology: A Perspective with Chemistry Examples; ACS Symposium Series 622; American Chemical Society: Washington, DC, pp 1-18, 96.

10. Handbook of Nanostructed Materials and Nanotechnology Volumes 1-5; Nalwa, H. S., Ed.; Academic Press: New York, 2000.

11. Lecture Notes on Fullerene Chemistry: A Handbook for Chemists;Taylor, R., Ed.; Imperial College Press: London, 1999.

12. Science and Application of Nanotubes (Fundamental Materials Research); Tomanek, D.; Enbody, R. J., Ed.; Plenum Publishing: New York, 2000.

13. Dresselhaus, M. Physics World, May 1996, 18-19.

14. Iijima, S., Nature 1991, 354, 56-58.

15. Ebbesen, T.; Ajayan, P.; Nature 1992, 358, 220-222.

16. Hersam, M. C. Nanotechnology 2000, 11 (2), 70-76.

17. Takeda, Y. Nuclear Instruments \& Methods In Physics Research Section B: Beam Interactions With Materials And Atoms 2000, 166, $877-881$

18. Oku, T. Microelectronic Engineering 2000, 51 (2), 51-60.

19. Kim, Y. K. Synth. Met.; 2000, 111 (June 1), 207-211.

20. Barnes, K. A. Macromolecules 2000, 33 (11), 4177-4185.

21. Rotkin, S. V. Phys. Lett. A 1999, 261 (1-2), 98-101. 
22. Saito, Y. J. Cryst. Grwth., vol 187 no 3-4, pp.402-409, May 1998.

23. Liu M. G.; Crowely A., Carbon, vol 33 no 6, pp.749-756, 95.

24. Kinoshite, K. Carbon, Electrochemical and Physicochemical Properties; Wiley Interscience: New York, 1988, p 207.

25. Kinoshite, K., Carbon, Electrochemical and Physicochemical Properties, Wiley Interscience: New York, 1988, p 215.

26. Dresselhaus, M. S.; Dresselhaus, G. Adv. Phys. 1981, 30, 139-326.

27. Anderson, S. H.; Chung, D. Carbon 1984, 22, 253-256.

28. Martin, W.; Brocklehurst, J. Carbon 1964, 1, 133-139.

29. Mazieres, C.; Colin, G.; Jegoudez, J.; Setton, R. Carbon 1975, 13, 289-293.

30. Mazieres, C.; Colin, G.; Jegoudez, J.; Setton, R. Carbon 1976, 14 176-184.

31. Stevens, R. E.; Ross, S.; Wesson, S. P.; Carbon 1973, 11, 525.

32. Dowell, M. B. Ext. Abs. Program, $12^{\text {th }}$ Bienn. Conf. Carbon, 1975, 31.

33. Mikami, H., Japanese Patent 76-96,793, 1976.

34. Inagaki, M.; Muramastu, K.; Maeda, Y.; Maekawa, K. Synth. Met. 1983, 8, 335 .

35. Berger, D.; Maire, J. Mater. Sci. Eng. 1977, 31, 335.

36. Union Carbide, U.S. Patent No. 3,404,061, 1968.

37. Jenkins, G.; Kawamura, K. Polymeric Carbons: Carbon Fibre, Glass, and Char, Cambridge University Press: New York, 1976, p $138 \mathrm{ff}$.

38. Kipling, J.; Shewood, J.; Shooter, P. Carbon 1964, 1, 315-318.

39. Thomy, A.; Duval, X.; J. de Chimie Phys. 1969, 66, 1966-1971.

40. Yamada, S. A Review of Glasslike Carbons; Battelle Memorial Institute: Ohio, 1968.
41. Hiura, H.; Ebbesen, T.; Tanigaki, K.; Takahashi, H. Chem. Phys. Lett. 1993, 202, 509.

42. Chandrabhas, N.; Sood, A.; Sundararaman, D.; Raju, S.; Rao, G. Pramana J. Phys. 1994, 42, 375.

43. Jishi, R.; Venkataraman, L.; Dresselhaus, M.; Dresselhaus, G. Chem. Phys. Lett. 1993, 209, 77.

44. Wang, J. Electrochem. Acta 1981, 26, 1721.

45. Jorissen, L.; Schliermann, T.; Trapp, V; Schutz W; Bohmhammel, K; Wolf, G; Garche, J. J. Power Sources 1999, 84 (2), 221-224.

46. Bauschlicher, C. W. Chem. Phys. Lett. 2000, 322 (3-4), 237-241.

47. Zuttel, A; Chartouni, D; Schlapbach, L. Electrochem and Solid St. Lett. 1999, 2 (1), 30-32.

48. Manning, T; Mitchell, M.; Gaddy, G.; Miller, A.; Grow, W.; Stach, J.; Riddle, K.; Vicker, T. In Science and Application of Nanotubes (Fundamental Materials Research); Tomanek, D.; Enbody, R. J., Eds. Plenum Publishing: New York, 2000;

49. Manning, T.; Mitchell, M.; Gaddy, G. Production of Nanostructures from an Inductively Coupled Plasma. U.S. Patent Appl.

50. Manning, T.; Mitchell, M.; Stach, J.; Vickers, T. Carbon 1999, 37 , 1159-1165.

51. J. M. Pigos, J. M.; Musfeldt, J. L. Chem. Educator 1998, 3 (4), S1430-4171(98)04233-4; DOI 10.1007/s00897980233a.

52. West, S. P. J. Chem. Educ. 1997, 74 (3), 311-312.

53. Hildebrand, A. J. Chem. Educ. 1996, 73 (11), 1066-1067.

54. Almy, J. J. Chem. Educ. 1996, 73 (5), A105-A 106.

55. Zumwalt, M. C. J. Chem. Educ. 1995, 72 (10), 939-940.

56. Boo. W. O. J. Chem. Educ. 1992, 69 (8), 605-609.

57. Beaton. J. M. J. Chem. Educ. 1992, 69 (8), 610-612.

58. Smestad, G.P. J. Chem. Educ. 1998, 75 (6), 752-756. 